\title{
Optimization of Research and Methodology Work at University in Terms of the Process Approach
}

\author{
Ibragim D. Ibragimov ${ }^{1}$, Rezeda R. Iskhakova ${ }^{2}$, Mariam A. Galeeva ${ }^{3}$, Milyausha M. Kalashnikova ${ }^{3}$, Julia V. \\ Ryseva $^{3}$, Ilkhamiya I. Galimzyanova ${ }^{4}$ \& Ivan A. Sharonov ${ }^{5}$ \\ ${ }^{1}$ Pyatigorsk State Linguistic University, Pyatigorsk, Russia \\ ${ }^{2}$ Kazan National Research Technological University, Kazan, Russia \\ ${ }^{3}$ Kazan (Volga region) Federal University, Kazan, Russia \\ ${ }^{4}$ Kazan State Conservatoire (Academy) named after N. Zhiganov, Kazan, Russia \\ ${ }^{5}$ Ulyanovsk State Agricultural Academy named after P. A. Stolypin, Ulyanovsk, Russia \\ Correspondence: Ibragim D. Ibragimov, Pyatigorsk State Linguistic University, 357532, Kalinina Prospect, 9 , \\ Pyatigorsk, Russia. E-mail: 001612@mail.ru
}

\author{
Received: May 7, 2015 Accepted: May 16, 2015 Online Published: May 28, 2015 \\ doi:10.5539/jsd.v8n3p234 URL: http://dx.doi.org/10.5539/jsd.v8n3p234
}

\begin{abstract}
The objective of this article is to improve the research and methodology work at university providing regulatory and instructional work of university teachers. The submitted article presents a way of managing a scientific methodological work in terms of process approach that ensures quality of educational activities at university. The basis of the submitted work are the ideas of total quality management including the cycle of continuous activity improvement. The authors have developed the principles and process algorithm "Management of research and methodology work at university," diagnostic tools of evaluating university teachers' activity. This article is intended for educators, researchers, heads of educational institutions involved in design and management of research and methodology work in higher education.
\end{abstract}

Keywords: higher education, research and methodology work, process approach, diagnostics, improvement

\section{Introduction}

\subsection{Background}

Providing qualitative training of highly-professional specialists remains one of the objectives of the education system inseparable from social sphere. The major objectives of today's higher education are: education of a competent specialist competitive in the labor market, responsible, proficient in his profession and familiar with the related fields, capable of productive work, ready for continuous professional growth, social and professional mobility.

The Federal State Educational Standard of higher education aims at the following outcomes: achieving the specified quality of education, increasing competitiveness and professional mobility of the graduates in the labor market; building multi-level education, ensuring a close connection between theory and practice; developing the educational potential of the educational institution; developing democratization of management (Birch, 1983).

One of the areas of achieving these goals is implementation of research and methodology work in educational institutions of higher education that contributes to the quality of the educational process.

The research and methodology work is one of the teacher's functions that is directed towards improving the disciplines courseware which ultimately affects the graduates' qualitative training. Therefore, the level of scientific and methodology work of the university depends on teachers' professional competence together with the improvement of pedagogical technologies, methods and means of teaching disciplines by them (Krivykh, 2013).

\subsection{Status of a Problem}

Higher education should function in the mode of development, quickly and effectively solve the emerging psychological-pedagogical problems of the educational process, and therefore the system of higher education management should not only keep pace with the rapid changes in the education market and social partners requests, 
but also lead the way to make the processes of educational establishment manageable. A particular contribution to the competent, efficient and effective management of the development process of the educational establishment, management of its transition to a qualitatively new level of service is entrusted to the Scientific and Methodological Service through a qualitatively different arrangement of staffing, research, information, conceptual, courseware, regulatory supply of the educational process.

The issues of development of the educational process management theory have been discussed by the scientists (Abdrakhmanova, 2003; Gabdullin, 1991; Zvereva, 1997; Potashnik, 2006; Tretyakov, Shamova, 2005). The research of the scientists (Chernyakova, 2005; Shamova, 2005; Korchagin,2003; Moiseev, Moiseeva, 2004; Nemov, 1999; Potashnik, Lazarev,1995; Simonov,1995; Slastenin, 2004; Tretyakov, 2003; Zvereva,1997; Zaburyanova, 2006) and reveal the nature and role of methododology work in the education system, the functions of management in determining the prospects and the directions of its development, consider technological approaches to planning and organization a technological, research and methodology work. However, in our opinion, the applied functional approaches to the management of scientific and methodology work at university are ineffective, because they do not focus on the ultimate outcome of the whole educational process - training of a specialist.

\subsection{The Research Hypothesis}

The question of finding efficient methods of management of research and methodology work cannot be resolved within the framework of a functional approach used in higher education management systemas focus on the division of labor does not provide the necessary entirety of the educational activities and focus on customer satisfaction. The process approach possesses such kind of potential as it considers the management operations the continuous implementation of certain complex of interrelated activities and general management functions and has a focus on high-quality result, far-sighted use of resources, continuity and continuous improvement of the activities.

\section{Materials and Methods}

\subsection{The Objectives of the Research}

We have identified the following research objectives: 1) to present and justify theoretically the characteristics, structure and content of research and methodology work. 2) to determine the content and essence of the process approach in the management of research and methodology work in higher education. 3) develop an algorithm for the process of "Management of research and methodology work" in university 4) develop and implement a diagnostic management system of research and methodology work in higher education on the basis of the process approach.

\subsection{Research Methods}

To achieve the objectives and test the developed hypothesis we have applied the following methods: theoretical (analysis, synthesis, generalization, classification, modeling applied to the Federal State Educational Standard of higher education, teaching and curriculum documentation; academic and methodological research on this problem, legal and regulatory acts regulating educational activities and others.); empirical (interview, questionnaires, monitoring, expert evaluation method, the experiment); statistical (synthesis and processing of experimental data).

\subsection{The Basis of the Research}

The experiment was carried out from 2010 to 2014 at Kazan National Research Technical University named after A.N.Tupolev (KNRTU-KAI). The experiment involved the academic staff of Physics \& Mathematics Faculty, a total of 73 people.

\subsection{The Stages of the Research}

The study was conducted in three stages. At the first stage we studied the experience of research and methodology work management in professional educational establishments. Then we formulated the objectives, tasks, hypothesis of the research. The conceptual apparatus was also developed. At the second stage we identified the most important characteristics and developed the conceptual framework for managing research and methodology work as a process. There we searched for organizational conditions for functioning and development of the management system of research and methodology work on the basis of the process approach. At the third stage we analyzed the results of management of scientific and methodological work in terms of the process approach, performed the statistical analysis of the results and their qualitative interpretation.

\subsection{The Methodology of the Process Approach to the Management of Research and Methodology Work at University}

A multivariance of approaches to the management of educational process in educational establishments determine a variety of management methods. The objectives (outcomes) specify the components and interaction within in-out 
relation. Searching for the ways of optimal management of the educational activities should be based on a methodological approach that provides the basis of management and serves as a starting point. The peculiarities of the approach determine the priority of particular components and performance criteria of the educational process for the prime objective. We have defined the priority of quality of the educational processes that involves implementation of the theory of "Total Quality Management" in higher education.

The methodological origin of this theory and its technological implementation is based on the process approach including a description of typical components of educational activities and their characteristics, functional interaction, the technology of achieving the result. The advantage of the process approach lies in continuous management which it provides at the intersection of separate processes within the system as well as at their combination and interaction; discrete control since the management of every process is carried out separately from others and their interaction is caused by a chain of processes and in-out relations; the opportunity of continuous improvement both of a single process and their complex; the possibility of using a large number of quality assessment tools and methods within the model structure.

\section{Results}

\subsection{Determination of the Structure and Content of the Research and Methodology Work at University}

The authors have found that developing a system of management of research and methodology activities in the education system of XIX-XXI centuries (Buylova, Kochneva, 2001; Kravtsov,1986; Tretyakov, 2001; Sharanova, 2008; Shchepotin, 2008) discovers methodological foundations of historical and pedagogical research: the principles, approaches, forms, origin that have brought to the modern system of management of scientific and methodological work. The system represents a set of elements that are interrelated with each other and form a certain integrity, unity of all components.

The research and methodology work in the system of higher education is represented with the two types: academic and research activities. The academic work is the basis for organizing the university educational process, as it includes the development and implementation of basic professional educational programs, academic disciplines, interdisciplinary courses, modules. Structurally, a research and methododology work is holistic, open, dynamic, social and educational system, including: the legal framework, a set of quality requirements for university graduates education; human resources; a system of interaction between employers and educational establishment that provides cooperation in the field of practical training; courseware of the disciplines implementing competence-based approach to teaching; management system that meets modern requirements to the quality of research and methodology work in educational establishment.

A research work is carried out in two directions: a personal research activity of the teacher and tutoring the students' research activities. Following the theoretical findings (Birch, 1983; Kulagin, 2001; Litkens, 2009; Molchanov, 1998; Fishman, 1997) having studied the research and methodology literature including doctoral theses we have defined the concept of " research and methodology work" as the sphere of professional pedagogical work of the teacher providing new knowledge about the educational process resulting in a creative level of research and methodology competence of a teacher including knowledge, skills, professionally significant characteristics as well as the development and implementation of his own research and methodology products into the educational process of college. Precisely this understanding of the key category determines teacher's success. A theoretical analysis of scientific and research and methodology literature has allowed to identify the major personality components that meet modern requirements for the higher education teacher ensuring his success in research and methodological activities. We have identified six components at a minimum: motivational, activity, cognitive, communicative, axiological, reflective.

\subsection{The Application of the Process Approach in the Management of Research and Methodology at University}

The authors have justified the use of the process approach in managing the research and methodology work as the basis for its improvement while focusing on improving the quality and effectiveness of educational establishments.

The process approach is implemented in accordance with the principles of EFQM Excellence Model (EFQM European Fund of Quality Management) and the recommendations of ISO 9001: 2001 (Russian National Standard ISO 9000 - 2008) and focused on customers of educational services: graduates, employers, teaching staff, students, parents, society. It also regulates the educational process on the basis of an assessment of its condition according to the specified quality criteria for all components of the process and the factors that influence the final result. The process approach in managing the research and methodology work: 1) determines a scope of in -out relations within the cycle of scientific and methodological work (usually an academic year), allows for preventive and corrective actions; 2) significantly increases the effectiveness of goal-setting of the processes in educational establishments; 3 ) 
allows to have information about the initial state of the object before any stimulus, see the change while elaborating the previous stimulus and decide on the next action; 4) records the result of every process in written form thus guaranteeing its final result.

Initially, it is necessary to split the entire educational process into subprocesses and determine their hierarchy according to the ISO documents: identifying the core and secondary processes; optimizing the number of processes: basic processes make no more than $7 \pm 2$, and supportive $-5 \pm 2$; identification of those responsible for the effectiveness of every process; providing necessary resources and process performance indicators; coordination, i.e. the overall management of all processes. The abovementioned procedures make it possible to visualize the structural content of the principles of the process approach, its customers, suppliers, management actions and the work mechanism.

\subsection{The Algorithm of the Process "Management of the Research and Methodology Work"}

In accordance with the methodology of the process approach, every process is implemented according to the "quality loop": planning - implementation - monitoring - improvement. Therefore, Figure 2 presents a flowchart of the sequence of process activities "Management of research and methodology work."

Since the intention of the process approach is to increase the effectiveness of the establishment functioning [131; $136 ; 207]$, then as applied to the university - it means the increased efficiency of the "out" process - improving stakeholders' satisfaction. It is logical that in order to ensure high quality «out» it is necessary to provide high quality of the process itself and the «in» since without a high quality of at least one of these components high quality result will not be provided. Understanding of the postgraduate teacher education as teachers' continuous development increases the importance of research and methodology work of professional educational establishment Moreover, in accordance with the objectives of research and methodology work management, the results appear in teacher's improved competence, which in turn contributes to the quality of the educational process in higher education. 


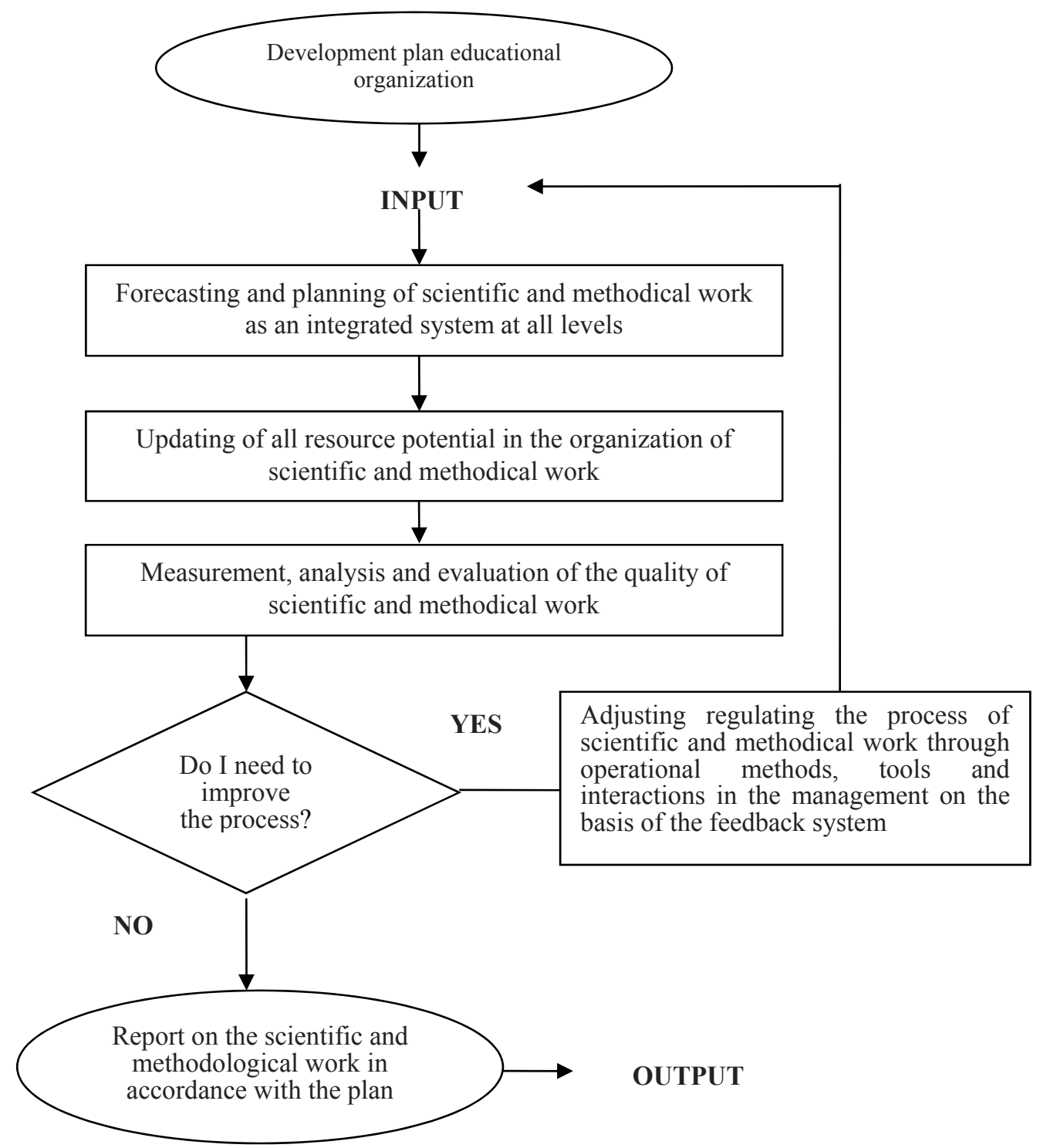

Figure 1. The process algorithm "Management of research and methodology work"

\subsection{The Diagnostic System of Research and Methodology Work Management}

To assess the impact of the technology management of research and methodology work on the basis of the process approach developed through the diagnostic system means to assess the process within the developed criteria and indicators to determine the success of its operation. A diagnostic system reflects the axiological, motivational, structurally-technological, managerial, assessing, qualitative and quantitative indicators providing a dynamic awareness, sustainability, effectiveness and efficiency of scientific and methodological work.

This system includes:

- Assessment of the human resources in the process - the academic staff (provision, efficiency and effectiveness) and the students (provision, satisfaction, the quality of training);

- Process effectiveness assessment (management success, the conditions for teachers involvement, control technology quality).

The experimental work was carried out on the basis of diagnostic procedures through the "assessment of resources", "process assessment" and "management assessment “.

The assessment of the resources through expert ranking has been shown: the teaching staff qualifications is fully 
consistent with the needs of the educational program and is used efficiently according to their education and training; the percentage of the teaching staff turnover dropped to $15 \%$; professional development of the teaching staff has acquired a systematic character (Fig. 2); the positive performance dynamics according to the indicators of the research and methodology work management concerning students' involvement and performance indicators in terms of the exam results. It is the process-based approach that allows to understand that the final result of pedagogical activity is the result of joint work of all the employees. Moreover, it eliminates the gaps at the processes intersection restoring the connection between them.

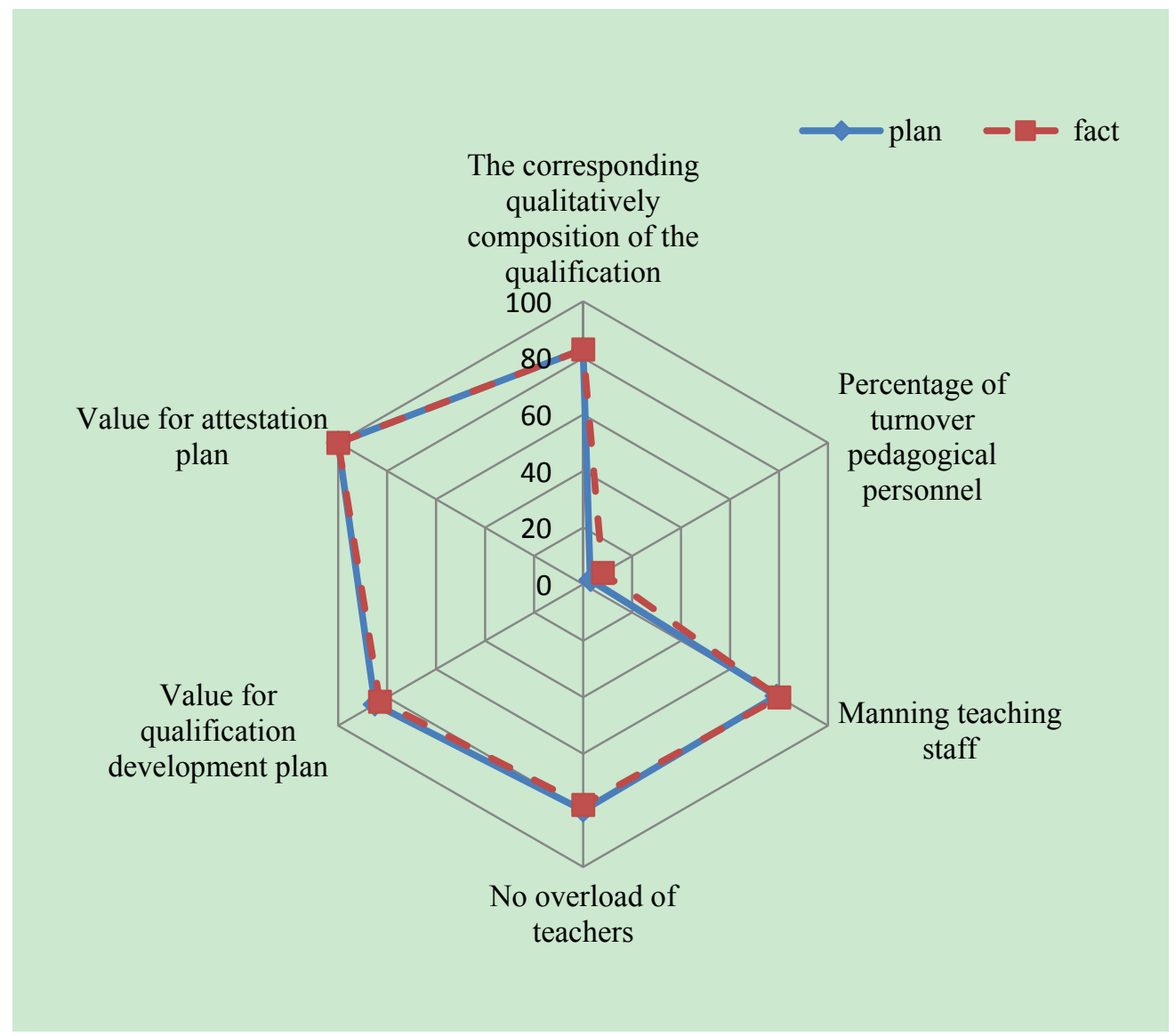

Figure 2. The human resources performance (academic staff)

On the ground of the process results (Table 1/) we have determined the effectiveness of the control system in the development of research and methodology work in creating conditions for teachers' involvement to ensure the quality of the educational process and management technology.

Thus, it is proved that, firstly, the process of "management of research and methodology work" stays in line with the strategic objectives of the university; secondly, there is an objective connection between the controlled characteristics at the incoming process and the results; third, the management resources of research and methodology work have been identified ; fourth, the results of the process correspond the planned results, the results obtained in the course of the experimental work confirm the developed hypothesis and show the efficiency of research and methodology work management on the basis of the process approach in higher education. 
Table 1. The performance process assessment of "Research and methodology work management" for 2014

\begin{tabular}{lcc}
\multicolumn{1}{c}{$\begin{array}{c}\text { performance of the process } \\
\text { "Research and methodology work management " }\end{array}$} & plan & fact \\
\hline Quality evaluation system the process & $95 \%$ & $80 \%$ \\
Quality information support system & $80 \%$ & $72 \%$ \\
The number of teachers involved in the management process & $50 \%$ & $30 \%$ \\
The effectiveness of management decisions & $80 \%$ & $72 \%$ \\
The adequacy of the organizational structure & $80 \%$ & $70 \%$ \\
Quality planning of scientific and methodical department & $95 \%$ & $80 \%$ \\
Satisfaction with the system of professional development of teachers & $80 \%$ & $72 \%$ \\
The level of development of innovative educational technologies & $50 \%$ & $38 \%$ \\
Satisfaction with working conditions of teachers & $80 \%$ & $62 \%$ \\
Satisfaction of teachers their scientific and methodical work & $80 \%$ & $74 \%$ \\
Level of motivation of teachers & $80 \%$ & $69 \%$ \\
\hline
\end{tabular}

\section{Discussions}

A research and methodology work is a part of the methodic work and is focused on achieving and maintaining high quality of the educational process, it contributes to the development of pedagogical analytic skills, theoretical and experimental research, organically joins the daily practice of the teacher. The specificity of organization of research and methodology work in professional educational establishments as an open dynamic socio-pedagogical system: the presence of the legal-base; availability of the human resource of different levels of training; a system of interaction with the employers; availability of the disciplines models and educational software, implementing modular competence-based approach; the presence of a management system that meets modern requirements to the quality of research and methodology work at university.

\section{Conclusions}

The social need for highly qualified teachers who have social and professional competence in the field of research and methodology work is connected with the socio-economic, political and cultural changes that are a characteristic feature of present-day Russia. These changes cause modern management requirements to the research and methodology work in universities and to the teachers, their realization within innovative methodological approaches one of which is the process approach.

The research and methodology work management on the basis of the process approach is an innovative course in solving important issues of Federal State Educational Standard of higher education, in achieving the teaching goals through the detailed study of the problem, its designing towards real, tangible practical result, ready for introduction into the university educational process.

\section{Acknowledgments}

The authors thank all participants of this study for their kind cooperation.

\section{References}

Abdrakhmanova, G. S. (2003). Diagnostics management efficiency school. Journal of Tatar-American Regional Institute, 128.

Birch, E. S. (1983). Guide modern school. Publisher House "Education", 207.

Buylova, L. N., \& Kochneva, S. V. (2001). Organization methodical service agencies additional education. Publishing Center "Vlados", 160.

Chernyakova, N. N. (2005). Methodical service as a condition for the development of the teaching staff of private educational institution education. PhD Thesis. Ekaterinburg, 165.

Fishman, L. I. (1997). Theoretical bases of management of educational systems: Textbook Kazan. Publishing Center "ASIC RAO", 160.

Gabdullin, G. G. (1991). Organizational-pedagogical bases restructuring intraschool managemen. The 
dissertation author's doctor of pedagogical sciences, 43.

Konarzhevsky, Y. A. (1997). Technology of pedagogical analysis of the educational process. Journal of inbox Center Search, 77.

Korchagin, E. A. (2003). Problems of quality management of vocational education students. Control the quality of basic vocational education. Sat. scientific. Kazan, 47.

Kravtsov, N. I. (1986). Organization of methodical work in a vocational school and its leadership. Publisher House "Graduate School", 79.

Krivykh, V. V. (2013). The essence of the process approach in the management of scientific and methodical work in professional educational organizations. Kazan pedagogical journal, 5, 98.

Kulagin, E. A. (2001). Pedagogical conditions of efficiency of educational process in vocational schools. Dissertation candidates of pedagogics sciences. Yekaterinburg, 189.

Litkens, K. Y. (2009). Organization of scientific and methodical work of teachers gymnasium № 1541 of the Western District of Moscow. Publisher House "September", 136.

Mishin, V. M. (2009). Quality Management: A textbook for university students enrolled in "Management of the organization Publishing Center "Unity-Dana", 463.

Moiseev, A. M., \& Moiseeva, O. M. (2004). Deputy Director of the School for Scientific and methodical work: functions, powers, technology activities. Russian Pedagogical Society, 256.

Molchanov, S. G. (1998). Theory and practice of certification of teaching and leading employees of educational institutions. The dissertation author's doctor of pedagogical sciences. Chelyabinsk, 316.

Nemov, N. V. (1999). Management of methodical work at school. Publisher House "September", 176.

Potashnik, M. M. (2004). Quality management education: practice-monograph and textbook. Journal of Russian Pedagogical Society, 448.

Potashnik, M. M. (2006). Quality management education. Publisher House "Russian Pedagogical Society", 448.

Sailor, D. Sh. (2008). Quality management in the school on the basis of a series of standards of GOST R ISO 9000-2001. New information technologies and educational monitoring. Center for Teacher Education, 288.

Shamova, T. I. (2005). Management of educational systems. Publishing center "Academy", 384.

Sharanova, V. V. (2008). Improvement of scientific and methodical work as a factor in improving the quality of education "Secondary school № 2". Aldan deputy. Publishing Center "Director", 105.

Shchepotin, A. F. (2008). An effective system of methodical work with teachers. Publishing Center "Professional education", 98.

Simonov, V. P. (1995). Educational management. 50 know-how in the field of educational management. Textbook, 226.

Slastenin, V. A. (2004). Pedagogy of vocational education: teaching aid for students. Executive. ped. Proc. institutions. Publishing Center "Academy", 368.

Tretyakov, P. I. (2003). Adaptive management of teaching systems. Publishing Center "Academy", 368.

Zaburyanova, V. D. (2006). Scientific and methodological support of professional training of secondary vocational education: dissertation candidates of. pedagogical science. Moscow, 201.

Zvereva, V. I. (1997). Organizational and pedagogical activity of the head of the school (2nd ed.). Journal of New School, 320.

\section{Copyrights}

Copyright for this article is retained by the author(s), with first publication rights granted to the journal.

This is an open-access article distributed under the terms and conditions of the Creative Commons Attribution license (http://creativecommons.org/licenses/by/3.0/). 